\title{
PENGARUH BUDAYA TEKNOLOGI INFORMASI TERHADAP KESUKSESAN KEWIRAUSAHAAN DIGITAL PADA WIRAUSAHA DI JAKARTA
}

\author{
Michelle Louie dan Franky Slamet \\ Program Studi Manajemen Fakultas Ekonomi \& Bisnis Universitas Tarumanagara, Jakarta \\ <michelle.115170302@stu.untar.ac.id>
}

\begin{abstract}
ABSTRAK: Tujuan dari penelitian ini yaitu untuk mengetahui: 1) pengaruh budaya teknologi informasi terhadap kesuksesan kewirausahaan digital, 2) keinovatifan seseorang yang mempengaruhi hubungan antara budaya teknologi informasi dengan kesuksesan kewirausahaan digital, 3) pengalaman yang mempengaruhi hubungan antara budaya teknologi dengan kesuksesan kewirausahaan digital. Teknik pemilihan sampel yang digunakan pada penelitian ini yaitu nonprobability sampling dan menggunakan teknik convenience sampling. Pengumpulan data menggunakan kuesioner yang didistribusikan melalui internet dengan google form dengan total 130 responden namun hanya 110 data yang dapat digunakan. Pengolahan data dalam penelitian ini menggunakan SmartPLS v.3.3.3. Sampel dalam penelitian ini yaitu wirausaha yang berdomisili di Jakarta yang memiliki bisnis dalam bidang pakaian, kuliner, kecantikan, dan elektronik dengan rentang usia 18-45 tahun. Hasil analisis dari penelitian ini yaitu: 1) budaya teknologi informasi terbukti berpengaruh secara positif dan signifikan terhadap kesuksesan kewirausahaan digital, 2) keinovatifan seseorang terbukti berpengaruh secara positif dan memoderasi hubungan antara budaya teknologi informasi dengan kesuksesan kewirausahaan digital secara semu, 3) pengalaman terbukti berpengaruh secara positif dan memoderasi hubungan antara budaya teknologi informasi dengan kesuksesan kewirausahaan digital secara semu.
\end{abstract}

ABSTRACT: The purpose of this study is to determine: 1) the impact of information technology culture on digital entrepreneurship success, 2) the impact of personal innovativeness that affects the relationship between information technology culture and digital entrepreneurial success, 3) the impact of experiences that affect the relationship between information technology culture and digital entrepreneurship success. The sampling technique used in this research is non-probability sampling and convenience sampling technique. Data in this research was collected by using a questionnaire and distributed via the google form with 130 respondents but only 110 data that can be used. Data in this research was processed by using SmartPLS v.3.3.3. The sample in this study are entrepreneurs based in Jakarta and have businesses in the clothing, culinary, beauty, and electronics fields with 18-45 years age range. The results of this study are: 1) information technology culture has a positive and significant effect on digital entreprene urship success, 2) personal innovativeness has a positive and significant effect, also moderates the relationship between information technology culture and digital entrepreneurship success, 3) experience has 
positive and significant effects also moderates the relationship between information technology culture and digital entrepreneurial success.

Keywords: Budaya teknologi informasi, Keinovatifan seseorang, Pengalaman, Kesuksesan kewirausahaan digital, Kewirausahaan digital

\section{LATAR BELAKANG}

Perkembangan industri digital yang meningkat akhir-akhir ini di Indonesia dapat menjadi pemicu bertambahnya perluasan dalam sektor industri digital hingga 60 persen dalam empat tahun terakhir. Adapun segmen perusahaan yang diprediksi akan menyumbang lowongan pekerjaan terbesar di sektor teknologi digital ini, antara lain e-commerce, teknologi keuangan (fintech), logistik, dan big data (Kemenperin, 2017). Platform digital memberikan banyak peluang untuk wirausaha yang melibatkan pengembangan produk dan layanan pelengkap. Teknologi digital semakin menjadi bagian yang tidak terpisahkan dari peluang kewirausahaan baik dari segi hasil maupun prosesnya (Nambisan, 2017). Menurut Abubakre (2020), penyesuaian setiap individu terhadap perkembangan industri digital merupakan unsur penting yang sebaiknya dapat ditumbuhkan dan dikembangkan sejak sedini mungkin dengan tujuan agar seseorang dapat menghadapi dan mempersiapkan diri pada situasi dan kondisi tertentu di masa yang akan datang dengan menjalankan sebuah bisnis khususnya dalam kemajuan budaya teknologi informasi. Susan dan Acs (2017) mendefinisikan bahwa pengusaha digital sebagai individu yang melakukan praktik dan aktivitas untuk menyampaikan suatu produk atau layanan, terutama melalui teknologi digital dengan sedikit atau tanpa keterlibatan dengan komponen fisik yang dominan. Oleh karena itu, Liu et al (2018) mendefinisikan bahwa proyek kewirausahaan digital cenderung dipengaruhi oleh keinovatifan seseorang dalam teknologi informasi dan nilai-nilai budaya teknologi informasi. Individu yang menunjukkan kepercayaan diri tinggi dan berani terhadap pengambilan risiko akan menunjukkan tipe kepribadian yang bersedia berinovasi dengan teknologi informasi, (Yuan et al, 2020). Lebih lanjut, Liu et al (2018) mengatakan bahwa pengalaman-pengalaman sebelumnya dalam teknologi informasi penting untuk mengembangkan kemampuan dan pengetahuan untuk mengatasi masalah bisnis khususnya yang terlibat dalam bidang teknologi informasi untuk mewujudkan kesuksesan kewirausahaan digital. Berdasarkan latar belakang yang telah dijelaskan, maka akan dilakukan penelitian lebih lanjut terkait "Pengaruh Budaya Teknologi Informasi terhadap Kesuksesan Kewirausahaan Digital Pada Wirausaha di Jakarta dengan Keinovatifan Seseorang dan Pengalaman sebagai Variabel Moderasi”"

\section{KAJIAN TEORI}

Kewirausahaan digital merupakan subkategori kewirausahaan di mana sebagian atau semua hal yang bersifat fisik dalam organisasi tradisional, telah terdigitalisasi karena ketersediaan dan penerapan digital teknologi yang memungkinkan adanya bentuk kewirausahaan baru (Nambisan, 2017). Susan dan Acs (2017) memperluas pandangan mengenai kewirausahaan digital dengan menyorot tampilan yang berpusat pada wirausaha. Hal ini menunjukkan bahwa wirausaha 
akan memanfaatkan teknologi digital untuk mencari dan menindaklanjuti peluang kewirausahaan secara efektif dan efisien.

\section{Budaya Teknologi Informasi}

Menurut Gallivan \& Srite (2005), budaya teknologi informasi adalah keyakinan dan nilainilai mengenai teknologi informasi yang memasuki kelompok masyarakat, yang telah diteliti dari berbagai perspektif seperti budaya nasional, etnis, organisasi, dan profesional. Nilai-nilai budaya dalam teknologi informasi didefinisikan sebagai penentuan perilaku memotivasi untuk memuaskan kebutuhan individu. Dengan demikian, budaya teknologi informasi individu dinilai dengan mengeksplorasi kebutuhan universal individu dan terpenuhi atau tidaknya penggunaan teknologi informasi (Walsh, 2014).

\section{Keinovatifan Seseorang}

Keinovatifan seseorang didefinisikan sebagai tingkat di mana seseorang relatif lebih awal dalam mengadopsi suatu inovasi daripada anggota lain dari sistem sosialnya (Abubakre et al, 2020). Agarwal \& Prasad (1998) mengemukakan bahwa keinovatifan seseorang dalam domain teknologi informasi didefinisikan sebagai kesediaan individu untuk mencoba teknologi informasi baru. Lebih lanjut, menurut Agarwal \& Prasad (1998), keinovatifan seseorang dalam teknologi informasi membantu mengidentifikasi individu yang cenderung mengadopsi inovasi teknologi informasi lebih awal dari yang lain. Pada tingkat umum, inovasi adalah suatu fungsi dari toleransi individu terhadap risiko tertentu dan individu lebih cenderung berinovasi jika mau mengambil risiko tersebut (Thatcher et al, 2016).

\section{Pengalaman}

Pengalaman adalah aliran persepsi dan interpretasi individu dari satu atau beberapa peristiwa. Pengalaman tidak mencakup semua yang pernah dialami seseorang di masa lalu, tetapi disebut sebagai faktor pengaruh manusia, (Brunnström et al (2013). Pengalaman dari wirausaha digital dengan kompetensi, keahlian, dan pengetahuan yang berkembang cenderung memiliki kemampuan untuk memanfaatkan potensi keterbukaan dan kemampuan untuk menavigasi lingkungan digital yang dinamis dan kompleks (Nambisan et al., 2019). Lebih lanjut, Batjargal (2007) menyatakan untuk melengkapi gambaran karakteristik wirausaha digital, pengalaman kerja seseorang sebelumnya mempengaruhi pencapaian hasil kewirausahaan digital yang sukses. Para ahli telah melaporkan bahwa pengalaman adalah faktor mikro yang berguna yang dapat mempengaruhi kesuksesan kewirausahaan.

\section{Kesuksesan Kewirausahaan Digital}

Menurut Selamat et al (2020), pengusaha perlu mempersiapkan rencana bisnis dengan matang dan memiliki pemikiran kritis terhadap berbagai isu yang berkembang di dunia budidaya bisnis. Lebih lanjut, Vesper (1990) mengemukakan definisi keberhasilan wirausaha memiliki keberadaan yang beragam di mana pemahaman tentang sukses juga berbeda. Seorang wirausaha menganggap sukses jika pendapatan lebih tinggi, sedangkan wirausaha lain mungkin percaya bahwa sukses sama dengan membuktikan keefektifan seseorang.

\section{Kaitan antara Budaya Teknologi Informasi dan Kesuksesan Kewirausahaan Digital}


Dalam penelitian yang dilakukan sebelumnya oleh Nambisan (2017) menyatakan bahwa kesuksesan kewirausahaan digital bersifat dinamis dan lancar karena perubahan ruang lingkup yang konstan, fitur teknologi digital, dan nilai penawaran produk atau layanan. Lebih lanjut, Walsh et al (2010) menyatakan bahwa penggunaan teknologi digital oleh pengusaha dapat didasarkan pada kebutuhan dan motivasi mereka dengan menggunakan fitur teknologi untuk mencapai tujuan mereka.

\section{Kaitan antara Keinovatifan Seseorang dan Kesuksesan Kewirausahaan Digital}

Dalam penelitian sebelumnya, Abubakre (2020) mengemukakan bahwa seseorang dengan keinovatifan yang lebih tinggi cenderung memiliki persepsi yang lebih kuat tentang penggunaan teknologi informasi, yang mengarah pada niat positif dan kesuksesan kewirausahaan digital. Menurut Agarwal \& Prasad (1999), dalam domain teknologi informasi, keinovatifan seseorang merupakan kemauan individu untuk mencoba teknologi informasi yang baru. Lebih lanjut, Selamat et al (2018) mengungkapkan bahwa untuk menjadi sukses, wirausahawan membutuhkan keterampilan kewirausahaan seperti kepercayaan diri, kebutuhan untuk berprestasi, kecenderungan mengambil risiko, toleransi terhadap ambiguitas, locus of control internal, dan inovasi.

\section{Kaitan antara Pengalaman dan Kesuksesan Kewirausahaan Digital}

Pada penelitian sebelumnya, Liu et al (2018) melaporkan bahwa pengalaman sebelumnya sangat penting untuk mengembangkan pengetahuan dan keahlian dalam mengatasi masalah bisnis khususnya proyek teknologi informasi untuk mewujudkan kesuksesan wirausaha. Selain itu, menurut Kollmann et al. (2009) pengalaman yang berkembang dari waktu ke waktu cenderung memengaruhi keyakinan dan sikap seseorang, serta memengaruhi teknologi informasi dan masalah bisnis yang berefek pada kesuksesan kewirausahaan digital. Berdasarkan uraian di atas, maka dibentuk suatu kerangka teoritis sebagai berikut:

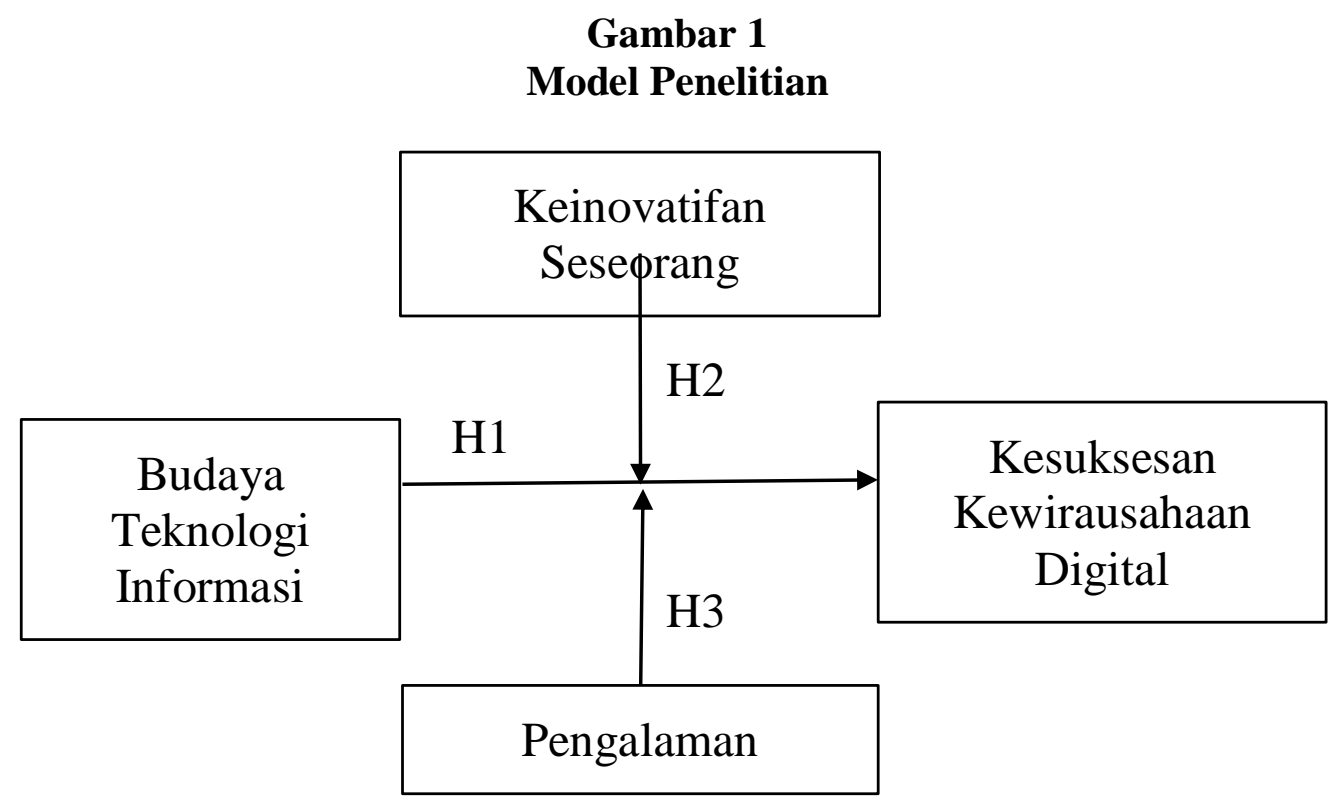


H1 : Budaya teknologi informasi berpengaruh secara positif terhadap kesuksesan kewirausahaan digital

H2 : Keinovatifan seseorang memiliki pengaruh secara positif terhadap hubungan antara budaya teknologi informasi dengan kesuksesan kewirausahaan digital

H3 : Pengalaman memiliki pengaruh secara positif terhadap hubungan antara budaya teknologi informasi dengan kesuksesan kewirausahaan digital

\section{METODOLOGI}

Desain penelitian yang digunakan untuk penelitian ini yaitu penelitian secara deskriptif ( descriptive study) karena dilakukan pengujian hipotesis yang dapat menganalisis hubungan antar variabel. Penelitian deskriptif ini menggunakan teknik cross-sectional studies dalam mengumpulkan data, di mana pengumpulan data hanya dilakukan sekali untuk menemukan hasil penelitian (Bryman, 2012). Jenis penelitian ini merupakan penelitian kuantitatif sehingga teknik analisis data yang digunakan adalah teknik analisis untuk data kuantitatif. Sedangkan dalam segi unit analisis, penelitian ini dilakukan secara individual, di mana data penelitian diperoleh dari individu berdasarkan preferensi dan pengalaman pribadi seseorang. Populasi yang digunakan sebagai subjek dari penelitian ini adalah pemilik usaha berbasis digital di Jakarta yang menggunakan marketplace sebagai sarana untuk berjualan. Pada penelitian ini akan dilakukan teknik non-probability sampling di mana tidak semua elemen dalam populasi dapat memiliki kesempatan untuk menjadi sampel. Di dalam teknik non-probability sampling, pemilihan sampel akan dilakukan dengan teknik convenience sampling. Teknik convenience sampling memilih sampel yang respondennya dipilih sesuai sehingga diharapkan dapat mempermudah penelitian yang dilakukan. Sampel dalam penelitian ini adalah wirausaha yang berdomisili di Jakarta yang memiliki bisnis dalam bidang pakaian, kuliner, kecantikan, dan elektronik dengan rentang usia 1845 tahun. Data yang telah terkumpul diolah menggunakan SmartPLS v.3.3.3. Pengumpulan data dilakukan dengan mendistribusikan kuesioner melalui internet dengan google form dan menggunakan skala likert dengan rentang poin 1-5. Mulai dari poin 1 yang berarti "Sangat Tidak Setuju" hingga poin 5 yang berarti "Sangat Setuju". Data yang terkumpul yaitu sebanyak 130 responden, namun hanya 110 data yang memenuhi kriteria dan dapat digunakan. Penelitian ini didominasi dengan responden yang berjenis kelamin perempuan yaitu sebanyak 72 responden $(65,46 \%)$, berusia $18-22$ tahun yaitu sebanyak 87 responden $(79,10 \%)$, tingkat pendidikan terakhir SMA/SMK yaitu sebanyak 66 responden (60\%), berdomisili Jakarta Barat yaitu sebanyak 75 responden $(68,18 \%)$, sudah menjalankan bisnis dalam 1-2 tahun sebanyak 48 responden $(43,64 \%)$, bidang bisnis fashion sebanyak 42 responden $(38,18 \%)$ dan menggunakan marketplace Shopee sebanyak 69 responden $(62,73 \%)$.

\section{HASIL ANALISIS DATA}

\section{Hasil Uji Validitas}

Menurut Sekaran dan Bougie (2013), uji validitas merupakan pengujian untuk menguji seberapa baik suatu instrumen yang dikembangkan dengan mengukur konsep tertentu terkait variabel dalam penelitian ini. Hasil dari uji validitas konvergen disajikan dalam Tabel 1 berikut: 
Tabel 1

Hasil Analisis Validitas Konvergen

\begin{tabular}{|c|c|c|}
\hline Variabel & $\begin{array}{c}\text { Average Variance } \\
\text { Extracted (AVE) }\end{array}$ & Keterangan \\
\hline Budaya Teknologi Informasi & 0,550 & Valid \\
\hline Keinovatifan Seseorang & 0,585 & Valid \\
\hline Pengalaman & 0,527 & Valid \\
\hline Kesuksesan Kewirausahaan Digital & 0,595 & Valid \\
\hline
\end{tabular}

Berdasarkan hasil analisis validitas konvergen di atas, Average Variance Extracted (AVE) dari setiap variabel yang ada dalam Tabel 1 adalah di atas 0.5 (> 0.5), maka keempat variabel tersebut memenuhi analisis validitas konvergen.

\section{Hasil Uji Reliabilitas}

Menurut Sekaran dan Bougie (2013), berdasarkan pernyataan tersebut, pengujian reliabilitas bertujuan untuk mengukur seberapa konsisten alat ukur yang mengukur konsep apapun. Hasil analisis Cronbach Alpha dan composite reliability akan disajikan dalam Tabel 2 berikut:

Tabel 2

Hasil Analisis Cronbach Alpha dan Composite Reliability

\begin{tabular}{|c|c|c|}
\hline Variabel & Cronbach Alpha & $\begin{array}{l}\text { Composite } \\
\text { Reliability }\end{array}$ \\
\hline Budaya Teknologi Informasi & 0,741 & 0,817 \\
\hline Keinovatifan Seseorang & 0,822 & 0,875 \\
\hline Pengalaman & 0,777 & 0,851 \\
\hline Kesuksesan Kewirausahaan Digital & 0,776 & 0,854 \\
\hline
\end{tabular}

Dalam Tabel 2 di atas dapat dilihat bahwa nilai dari masing-masing Cronbach's Alpha dan composite reliability berada di atas 0.7 (>0.7), maka variabel yang diteliti dinyatakan memenuhi reliabilitas konsistensi internal.

Pengujian Inner Model Analysis 


\section{Koefisien Determinasi}

Hasil dari analisis $R$ Square $\left(\mathrm{R}^{2}\right)$ dapat dilihat pada Tabel 3 di bawah ini:

\section{Tabel 3}

Hasil Analisis Koefisien Determinasi ( $R$ Square)

\begin{tabular}{|c|c|c|}
\hline Variabel & Nilai & Keterangan \\
\hline Kesuksesan Kewirausahaan Digital & 0,330 & Sedang \\
\hline
\end{tabular}

Berdasarkan Tabel 3, dapat dilihat bahwa keinovatifan seseorang dan pengalaman memiliki pengaruh moderat terhadap kesuksesan kewirausahaan digital (Chin, 1998). Hasil analisis $R$ Square $\left(\mathrm{R}^{2}\right)$ dari variabel kesuksesan kewirausahaan digital yaitu $33 \%$, dan sisanya sebesar $67 \%$ dapat dijelaskan atau dipengaruhi oleh variabel lain yang tidak terdapat dalam penelitian ini.

\section{Uji Pengukuran Q-Square}

Hasil analisis predictive relevance ditampilkan dalam Tabel 4 di bawah ini:

Tabel 4

Hasil Analisis Predictive Relevance (Q-Square)'

\begin{tabular}{|c|c|}
\hline Variabel & $Q$-Square \\
\hline Kesuksesan Kewirausahaan Digital & $\mathbf{0 , 1 7 3}$ \\
\hline
\end{tabular}

Berdasarkan Tabel 4, nilai dari $Q$-Square yang didapatkan yaitu $0,173\left(\mathrm{Q}^{2}>0\right)$ yang menandakan variabel yang diteliti dapat memprediksi model penelitian dengan baik.

\section{Uji Kecocokan Model}

Untuk melakukan uji Goodness of Fit, harus diketahui nilai AVE pada suatu penelitian. Nilai AVE pada suatu penelitian akan diuraikan pada tabel 5 berikut:

Tabel 5

Analisis AVE

\begin{tabular}{|c|c|}
\hline Variabel & AVE \\
\hline Budaya Teknologi Informasi & 0,550 \\
\hline Keinovatifan Seseorang & 0,585 \\
\hline Pengalaman & 0,527 \\
\hline
\end{tabular}




\section{\begin{tabular}{l|r} 
Kesuksesan Kewirausahaan Digital & 0,595
\end{tabular}} berikut:

Berdasarkan Tabel 5 di atas, dapat diketahui bahwa nilai AVE diperhitungkan sebagai

$$
\mathrm{AVE}=(0.550+0.585+0.527+0,595): 4=0,564
$$

Berdasarkan tabel $R$-Square $\left(\mathrm{R}^{2}\right)$ sebelumnya dapat diketahui bahwa nilai $R$-Square $\left(\mathrm{R}^{2}\right)$ adalah sebesar 0.330. Berdasarkan perhitungan smartPLS bagian $R$ adjusted maka nilai GoF sebesar:

$$
\begin{aligned}
& \mathrm{GoF}=\sqrt{A V E x R^{2}} \\
& \mathrm{GoF}=\sqrt{0,564 \times 0,330} \\
& \mathrm{GoF}=\mathbf{0 , 2 4 7}=\mathbf{0 , 2 5}
\end{aligned}
$$

Pada penelitian ini, Nilai GoF sebesar $\mathbf{0 . 2 5}$ memperlihatkan bahwa nilai atau tingkat kelayakan pada model penelitian ini dinyatakan sedang

\section{Hasil Pengujian Hipotesis}

Uji hipotesis path coefficients dan p-value akan ditampilkan pada Tabel 6 berikut:

\section{Tabel 6}

Tabel Hasil Bootstrapping

\begin{tabular}{|c|c|c|c|c|}
\hline Variabel & $\begin{array}{c}\text { Original } \\
\text { Sample }\end{array}$ & $\boldsymbol{t}$-statistics & $\boldsymbol{p}$-value & Keterangan \\
\hline BTI $\rightarrow$ KKD & 0,136 & 1,652 & 0,050 & Signifikan \\
\hline $\mathbf{K S ~} \rightarrow$ KKD & 0,186 & 1,674 & 0,047 & Signifikan \\
\hline $\mathbf{P} \rightarrow$ KKD & 0,379 & 3,341 & 0,000 & Signifikan \\
\hline
\end{tabular}

Berdasarkan Tabel 6, dapat dilihat bahwa nilai p-value yang didapatkan untuk variabel budaya teknologi informasi adalah sebesar 0.050 , untuk variabel keinovatifan seseorang adalah sebesar 0.047, dan variabel pengalaman adalah sebesar 0.000 yang menandakan variabel memiliki pengaruh positif yang signifikan terhadap variabel kesuksesan kewirausahaan digital. 


\section{PEMBAHASAN}

Dari hasil pengujian ketiga hipotesis tersebut, didapatkan hasil bahwa pada Hipotesis 1, budaya teknologi informasi terbukti berpengaruh signifikan secara positif terhadap kesuksesan kewirausahaan digital. Semakin tinggi pengaruh budaya teknologi informasi, maka akan semakin tinggi pengaruhnya terhadap kesuksesan kewirausahaan digital. Disamping itu, hasil penelitian ini juga didukung oleh Abubakre et al (2020) yang menyatakan bahwa budaya teknologi informasi berpengaruh positif dan signifikan terhadap kesuksesan kewirausahaan digital.

Selanjutnya pada Hipotesis 2, didapatkan hasil bahwa keinovatifan seseorang terbukti berpengaruh secara positif dan signifikan terhadap hubungan antara budaya teknologi informasi dengan kesuksesan kewirausahaan digital yang menandakan H2 tidak ditolak. Semakin tinggi tingkat keinovatifan seseorang, maka akan semakin tinggi pengaruhnya terhadap kesuksesan kewirausahaan digital. Hal ini sejalan dengan penelitian sebelumnya oleh Abubakre et al (2020), yang menyatakan bahwa keinovatifan seseorang yang lebih tinggi akan cenderung memiliki persepsi yang lebih kuat tentang penggunaan teknologi informasi yang mengarah pada kesuksesan kewirausahaan digital.

Pada Hipotesis 3, didapatkan didapatkan hasil bahwa pengalaman terbukti berpengaruh secara positif dan signifikan terhadap hubungan antara budaya teknologi informasi dengan kesuksesan kewirausahaan digital yang menandakan $\mathrm{H} 2$ tidak ditolak. Semakin banyak pengalaman yang dimiliki seseorang, maka akan semakin tinggi pengaruhnya terhadap kesuksesan kewirausahaan digital. Hal ini sejalan dengan penelitian yang telah dilakukan sebelumnya oleh Kollman et al (2009), yang mengemukakan bahwa pengalaman yang berkembang seiring waktu cenderung memengaruhi keyakinan dan sikap seseorang, serta memengaruhi teknologi informasi dan masalah bisnis yang dapat berefek pada kesuksesan kewirausahaan digital.

\section{KESIMPULAN}

Berdasarkan data yang telah dikumpulkan dan hasil yang telah di uji pada data tersebut, maka hasil analisis penelitian dapat disimpulkan sebagai berikut: 1) Budaya teknologi informasi terbukti berpengaruh secara positif terhadap kesuksesan kewirausahaan digital, 2) Keinovatifan seseorang terbukti berpengaruh secara positif dan memoderasi hubungan antara budaya teknologi informasi dengan kesuksesan kewirausahaan digital secara semu (quasi moderator), 3) Pengalaman terbukti berpengaruh secara positif dan memoderasi hubungan antara budaya teknologi informasi dengan kesuksesan kewirausahaan digital secara semu (quasi moderator). Dari hasil analisis data tersebut, maka ada beberapa saran yang dapat dikemukakan dan diharapkan dapat berguna bagi penelitian yang sejenis di masa yang akan datang. Berikut beberapa saran dan masukan yang dimaksud: 1) Wirausaha yang menjalankan bisnis berbasis digital perlu meninjau faktor-faktor dan aspek yang dapat mempengaruhi kesuksesan bisnis yang dijalankan. Hal ini dapat dilakukan dengan cara mau mempelajari dan terbuka terhadap hal-hal baru terkait budaya teknologi informasi, mengembangkan diri dengan mengasah keinovatifan dalam berbisnis serta memperbanyak pengalaman dalam bisnis. Selain itu diharapkan juga perusahaan e-commerce untuk menambah fitur-fitur baru yang dapat semakin memudahkan wirausaha dalam menjalankan bisnis berbasis digital seperti akses informasi yang mudah dan user interface yang efisien, 2) Untuk penelitian selanjutnya yang melakukan penelitian serupa, disarankan menggunakan variabel 
lain yang berpotensi untuk mempengaruhi variabel kesuksesan kewirausahaan digital seperti kecerdasan emosi, efikasi diri, dan niat berwirausaha. Kemudian selain meneliti wirausaha yang menjalankan bisnis berbasis digital, disarankan juga untuk meneliti marketplace yang menjadi media berjualan seperti Shopee, Tokopedia, Lazada, atau platform e-commerce lainnya sehingga diharapkan dapat menjadi lebih bermanfaat dan dapat menambah wawasan. Lebih lanjut, disarankan juga untuk melakukan pengumpulan data responden dengan jumlah yang lebih besar dan perluasan cakupan wilayah penelitian sehingga penelitian dapat menjadi lebih variatif dan dapat memberikan manfaat bagi pembaca.

\section{DAFTAR PUSTAKA}

Abubakre, M., Zhou, Y., \& Zhou, Z. (2020). The impact of information technology culture and personal innovativeness in information technology on digital entrepreneurship success. Information Technology \& People, ahead-of-print(ahead-of-print). https://doi.org/10.1108/itp-01-2020-0002

Agarwal, R., \& Prasad, J. (1998). A conceptual and operational definition of personal Innovativeness in the domain of information technology. Information Systems Research, 9(2), 204-215. https://doi.org/10.1287/isre.9.2.204

Abubakre, M., Zhou, Y., \& Zhou, Z. (2020). The impact of information technology culture and personal innovativeness in information technology on digital entrepreneurship success. Information Technology \& People, ahead-of-print(ahead-of-print). https://doi.org/10.1108/itp-01-2020-0002

Agarwal, R., \& Prasad, J. (1998). A conceptual and operational definition of personal Innovativeness in the domain of information technology. Information Systems Research, 9(2), 204-215. https://doi.org/10.1287/isre.9.2.204

Batjargal, B. (2007). Internet entrepreneurship: Social capital, human capital, and performance of internet ventures in China. Research Policy, 36(5), 605-618. https://doi.org/10.1016/j.respol.2006.09.029

Brunnström, K., Kulyk, V., Tavakoli, S., Folkesson, M., Wang, K., \& Garcia, N. (2013). 2013 fifth international workshop on quality of multimedia experience (QoMEX). https://doi.org/10.1109/qomex30796.2013

Bryman, A. (2015). Social research methods 4thedition. Oxford University Press.

Gallivan, M., \& Srite, M. (2005). Information technology and culture: Identifying fragmentary and holistic perspectives of culture. Information and Organization, 15(4), 295-338. https://doi.org/10.1016/j.infoandorg.2005.02.005

Kemenperin: Tumbuh 10 Persen, Generasi Milineal Dongkrak Industri digital. (n.d.). Kementerian Perindustrian. https://www.kemenperin.go.id/artikel/18581/Tumbuh-10Persen,-Generasi-Milineal-Dongkrak-Industri-Digital

Kollmann, T., Häsel, M., \& Breugst, N. (2009). Competence of IT professionals in E-business venture teams: The effect of experience and expertise on preference structure. Journal of Management Information Systems, 25(4), 51-80. https://doi.org/10.2753/mis0742$\underline{1222250402}$ 
Li, L., Su, F., Zhang, W., \& Mao, J. (2018). Digital transformation by SME entrepreneurs: A capability perspective. Information Systems Journal, 28(6), 1129-1157. https://doi.org/10.1111/isj.12153

Nambisan, S. (2017). Digital entrepreneurship: Toward a digital technology perspective of entrepreneurship. Entrepreneurship Theory and Practice, 41(6), 1029-1055. https://doi.org/10.1111/etap.12254

Nambisan, S., Wright, M., \& Feldman, M. (2019). The digital transformation of innovation and entrepreneurship: Progress, challenges and key themes. Research Policy, 48(8), 103773. https://doi.org/10.1016/j.respol.2019.03.018

Sekaran, U., \& Bougie, R. (2013). Research methods for business: A skill building approach. John Wiley \& Sons.

Sussan, F., \& Acs, Z. J. (2017). The digital entrepreneurial ecosystem. Small Business Economics, 49(1), 55-73. https://doi.org/10.1007/s11187-017-9867-5

Walsh, I. (2014). A strategic path to study IT use through users' IT culture and IT needs: A mixedmethod grounded theory. The Journal of Strategic Information Systems, 23(2), 146-173. https://doi.org/10.1016/j.jsis.2013.06.001

Walsh, I., Kefi, H., \& Baskerville, R. (2010). Managing culture creep: Toward a strategic model of user IT culture. The Journal of Strategic Information Systems, 19(4), 257-280. https://doi.org/10.1016/j.jsis.2010.09.002

Yuan, D., Lin, Z., \& Zhuo, R. (2016). What drives consumer knowledge sharing in online travel communities?: Personal attributes or E-sErvicE factors? Computers in Human Behavior, 63, 68-74. https://doi.org/10.1016/j.chb.2016.05.019

Batjargal, B. (2007). Internet entrepreneurship: Social capital, human capital, and performance of internet ventures in China. Research Policy, 36(5), 605-618. https://doi.org/10.1016/j.respol.2006.09.029

Brunnström, K., Kulyk, V., Tavakoli, S., Folkesson, M., Wang, K., \& Garcia, N. (2013). 2013 fifth international workshop on quality of multimedia experience (QoMEX). https://doi.org/10.1109/qomex30796.2013

Bryman, A. (2015). Social research methods 4thedition. Oxford University Press.

Gallivan, M., \& Srite, M. (2005). Information technology and culture: Identifying fragmentary and holistic perspectives of culture. Information and Organization, 15(4), 295-338. https://doi.org/10.1016/j.infoandorg.2005.02.005

Kemenperin: Tumbuh 10 Persen, Generasi Milineal Dongkrak Industri digital. (n.d.). Kementerian Perindustrian. https://www.kemenperin.go.id/artikel/18581/Tumbuh-10Persen,-Generasi-Milineal-Dongkrak-Industri-Digital

Kollmann, T., Häsel, M., \& Breugst, N. (2009). Competence of IT professionals in E-business venture teams: The effect of experience and expertise on preference structure. Journal of Management Information Systems, 25(4), 51-80. https://doi.org/10.2753/mis07421222250402

Li, L., Su, F., Zhang, W., \& Mao, J. (2018). Digital transformation by SME entrepreneurs: A capability perspective. Information Systems Journal, 28(6), 1129-1157. https://doi.org/10.1111/isj.12153 
Nambisan, S. (2017). Digital entrepreneurship: Toward a digital technology perspective of entrepreneurship. Entrepreneurship Theory and Practice, 41(6), 1029-1055. https://doi.org/10.1111/etap.12254

Nambisan, S., Wright, M., \& Feldman, M. (2019). The digital transformation of innovation and entrepreneurship: Progress, challenges and key themes. Research Policy, 48(8), 103773. https://doi.org/10.1016/j.respol.2019.03.018

Sekaran, U., \& Bougie, R. (2013). Research methods for business: A skill building approach. John Wiley \& Sons.

Selamat, F., Ie, M., Syahrivar, J., Chairy, C., \& Tunjungsari, H. K. (2020). Why I should run my own business: A study on female entrepreneurs' motivation and business success in Indonesia. Proceedings of the 8th International Conference on Entrepreneurship and Business Management (ICEBM 2019) UNTAR.

https://doi.org/10.2991/aebmr.k.200626.036

Selamat, F., Tunjungsari, H. K., Chairy, C., \& Utama, D. W. (2018). Entrepreneurial characteristics amongst different professional backgrounds: Evidence from Indonesia. International Journal of Business Studies, 2(1), 25-32. https://doi.org/10.32924/ijbs.v2i1.30

Sussan, F., \& Acs, Z. J. (2017). The digital entrepreneurial ecosystem. Small Business Economics, 49(1), 55-73. https://doi.org/10.1007/s11187-017-9867-5

Thatcher, J. B., Stepina, L. P., Liu, Y., \& Srite, M. (n.d.). Culture, Overload and Personal Innovativeness with Information Technology: Extending the Nomological Net. Journal of ComputerInformationSystems, 44:1,74-81.

https://doi.org/10.1080/08874417.2003.11647554

Vesper, K. H. (1990). New venture strategies. Prentice Hall.

Walsh, I. (2014). A strategic path to study IT use through users' IT culture and IT needs: A mixedmethod grounded theory. The Journal of Strategic Information Systems, 23(2), 146-173. https://doi.org/10.1016/j.jsis.2013.06.001

Walsh, I., Kefi, H., \& Baskerville, R. (2010). Managing culture creep: Toward a strategic model of user IT culture. The Journal of Strategic Information Systems, 19(4), 257-280. https://doi.org/10.1016/j.jsis.2010.09.002

Yuan, D., Lin, Z., \& Zhuo, R. (2016). What drives consumer knowledge sharing in online travel communities?: Personal attributes or E-sErvicE factors? Computers in Human Behavior, 63, 68-74. https://doi.org/10.1016/j.chb.2016.05.019 